\title{
Gli3 Is Required for Maintenance and Fate Specification of Cortical Progenitors
}

\author{
Hui Wang, ${ }^{1}$ Guannan Ge, ${ }^{1}$ Yutaka Uchida, ${ }^{2}$ Brian Luu, ${ }^{1}$ and Sohyun Ahn ${ }^{1}$ \\ ${ }^{1}$ Unit on Developmental Neurogenetics, Program in Genomics of Differentiation, Eunice Kennedy Shriver National Institute of Child Health and Human \\ Development and 2National Heart, Lung and Blood Institute, National Institutes of Health, Bethesda, Maryland 20892
}

Gli3, one of three vertebrate Gli transcription factors in Hedgehog $(\mathrm{Hh})$ pathway, is processed into a repressor form (Gli3R) in the absence of Hh signal and acts as the major negative transducer of the pathway. Although the role of Gli3 in embryonic patterning has been extensively studied, its role in cortical neurogenesis, especially in the regulation of neural progenitors in proliferation and cell fate specification, is largely unknown. To bypass the patterning defects caused by loss of Gli3, we conditionally deleted Gli3 after patterning was complete in mouse. Our results from birthdating and in utero electroporation experiments demonstrate that the Gli3, specifically Gli3R, is critical for specifying the fate of cortical neurons that are generated following a stereotypical temporal order. Moreover, Gli3 is required for maintaining the cortical progenitors in active cell cycle, suggesting that cells may acquire differentiated status as they turn off Gli3 expression during neurogenesis.

\section{Introduction}

Cortical neurogenesis takes place in the dorsal neuroepithelium of the telencephalon following the establishment of dorsoventral $(\mathrm{D} / \mathrm{V})$ patterning. Two distinct progenitor pools, the radial glial cells (RGCs) and intermediate progenitor cells (IPCs), undergo extensive proliferation to establish the neocortex (Götz and Huttner, 2005; Kriegstein and Alvarez-Buylla, 2009). Neuroepithelial cells divide symmetrically to increase the RGC pool in the ventricular zone (VZ) before embryonic day (E) 9-10 or divide asymmetrically to generate either IPCs or postmitotic neurons in addition to RGCs after E9-E10 (Götz and Huttner, 2005; Kriegstein and Alvarez-Buylla, 2009). In contrast, IPCs undergo limited numbers of symmetric divisions in the basal VZ or subventricular zone (SVZ) to generate either IPCs or postmitotic neurons (Noctor et al., 2004). Subsequently, later-born cortical neurons migrate past the older cortical neurons to form an inside-out laminar pattern of six distinct layers (McConnell, 1991). Whereas the neurons in deeper cortical layers (V/VI) can be generated directly from the RGCs or indirectly via the IPCs, the neurons in the upper cortical layers (II/III) are generated exclusively via the IPCs (Sessa et al., 2008).

\footnotetext{
Received Sept. 17, 2010; revised March 3, 2011; accepted March 9, 2011

Author contributions: H.W. and S.A. designed research; H.W., G.G., Y.U., B.L., and S.A. performed research; H.W., G.G., and S.A. analyzed data; H.W. and S.A. wrote the paper.

This work was supported by Intramural Research Program of National Institutes of Health. We thank Y. Zhao and members of Ahn laboratory for critical comments on the manuscript; A. Joyner, T. Haydar, B. Wang, and A. McMahon for providing mice and reagents; National Institute of Child Health and Human Development Microscopy and Imaging Core for the use of a confocal microscope; and T. Haydar for advice on in utero electroporation. We are especially grateful to M. Zervas, J. Li, and Y. Mukoyama for their comments and discussions during various stages of this work.

Correspondence should be addressed to Dr. Sohyun Ahn, Unit on Developmental Neurogenetics, Program in Genomics of Differentiation, Eunice Kennedy Shriver National Institute of Child Health and Human Development, National Institutes of Health, 9000 Rockville Pike 6B/2B220, Bethesda, MD 20892-2790. E-mail: ahnsohyun@ mail.nih.gov.

DOI:10.1523/JNEUROSCI.4892-10.2011

Copyright $\odot 2011$ the authors $\quad 0270-6474 / 11 / 316440-09 \$ 15.00 / 0$
}

Self-renewal or differentiation of neural progenitors is achieved by intricate genetic interactions and cell signaling pathways, including Shh (Hoch et al., 2009). Shh signaling is critical for establishing D/V patterning of developing neural tube (Fuccillo et al., 2006) and for progenitor proliferation and cell fate determination in ventral forebrain (Xu et al., 2005, 2010). As a downstream component of Shh signaling pathway, Gli3 is also required for $\mathrm{D} / \mathrm{V}$ patterning of neural tube and Gli3-null mice $\left(G l i 3^{X t / X t}\right)$ lose most of the dorsal telencephalon (Theil et al., 1999; Tole et al., 2000; Fotaki et al., 2006), preventing investigation of Gli3 function in later aspects of cortical development. The hypomorphic allele of Gli3 ( $p d n$ ) has a spared dorsal telencephalon (Friedrichs et al., 2008), but the phenotype could be the combinatorial effect of reduced level of Gli3 protein throughout development, including the patterning stage. In addition, Gli3 plays a bifunctional role as either a major negative effector (Gli3R) in the absence of Shh or as a weak activator in the presence of Shh (Wang et al., 2000); which form of Gli3 is critical for cortical development has not yet been clarified. In this study, we focused on the role of Gli3 in proliferation and differentiation of cortical progenitors and fate specification of cortical neurons using conditional genetic ablation to completely remove Gli3 in the developing nervous system after $\mathrm{D} / \mathrm{V}$ patterning is complete.

\section{Materials and Methods}

Mice. All mice used in this study were handled according to protocols approved by the Institutional Animal Care and Use Committee of the National Institutes of Health. Nestin-Cre (Tronche et al., 1999), Gli3 ${ }^{F /+}$ (Blaess et al., 2008), Gli3 ${ }^{X t /+}$ (Hui and Joyner, 1993), and ROSA26 ${ }^{R /+}$ (Soriano, 1999) mice were genotyped as described previously. Mice of either sex were used for the analysis; genotypes of controls and Gliz ${ }^{\text {cko }}$ mice were Nestin-Cre;Gli3 $3^{F /+} ;$ ROSA2 $6^{R /+}$ and Nestin-Cre;Gli3 ${ }^{F / X t}$; ROSA26 $6^{R /+}$, respectively.

Birthdating and cell cycle exit. Pregnant dams were injected with 200 $\mathrm{mg} / \mathrm{kg}$ body weight of BrdU at E15.5 or $20 \mathrm{mg} / \mathrm{kg}$ body weight of EdU (Invitrogen) at E14.5 for cell cycle exit and at E11.5, E13.5, E15.5, and 
E18.5 for birthdating experiments and analyzed at E16.5, E18.5, or postnatal day (P) 3 (see Results, below). For birthdating experiments, the number of BrdU+ cells was counted from a single optical section of confocal microscope images in 10 equally divided bins spanning the cortical thickness and expressed as a fraction of total number of BrdU+ cells per bin. For cell cycle exit study, confocal images were used to identify coexpression of EdU, BrdU, and Ki67.

In utero electroporation. E13.5 embryos of $\mathrm{Gli3}^{F / F} ;$ ROSA26 ${ }^{R / R}$ genotypes were electroporated in utero as described previously (Gal et al., 2006). Briefly, pregnant dams were deeply anesthetized with Nembutal and embryos in utero were injected with plasmid DNA exposed to visualize the lateral ventricle of the forebrain. In total, $4 \mu \mathrm{g}$ of DNA were injected into the lateral ventricle using a fine glass pipette needle. For loss-of-function experiments, either $4 \mu \mathrm{g}$ of RFP (red fluorescent protein) plasmid DNA or $3 \mu \mathrm{g}$ of DNA encoding Cre recombinase and $1 \mu \mathrm{g}$ of RFP plasmid were used. For the rescue experiment, pGli3R-IRESnGFP rescue construct was first generated by introducing Gli3R coding sequence (Wang et al., 2000) into pCIG vector containing IRES-nuclear GFP cassette (Megason and McMahon, 2002). Three micrograms of Cre DNA and $1 \mu \mathrm{g}$ of pGli3R-IRES-nGFP DNA were injected into the lateral ventricles. The embryos were electroporated with five $36 \mathrm{~V}$ pulses $(50 \mathrm{~ms}$ duration; each separated by $950 \mathrm{~ms}$ ) using a BTX ECM830 pulse generator. Embryos were allowed to develop until E18.5, at which time the they were removed and brains were dissected for further analysis.

Histology and immunohistochemistry. Whole heads (E12.5) and dissected brains from intact embryos (E14.5-E16.5) or transcardially perfused animals (E18.5 and neonates) were processed for frozen sections and immunostained as described previously (Ahn and Joyner, 2005). The primary antibodies used and their dilution factors were as follows: rabbit anti-Tbr1 (1:1000; Millipore), rabbit anti-Tbr2 (1:10,000; Millipore), rabbit anti-phospho-histone $\mathrm{H} 3$ (pHH3) (1:200; Millipore), rabbit antiCux1 (1:100; Santa Cruz Biotechnology), mouse anti-Satb2 (1:500; Abcam), mouse anti-MBP (1:1000; Covance), mouse anti-Nestin (1:100; Millipore), rabbit anti-Pax6 (1:500; Covance), mouse anti-BrdU (1:100; BD Biosciences), mouse anti-TuJ1 (1:500; Santa Cruz Biotechnology), rat anti-Ctip2 (1:500; Abcam), rabbit anti-GFP (1:600; Invitrogen), goat anti-LacZ (1:500; Biogenesis), and rat anti-Ki67 (1:100; Dako). The secondary antibodies used were species-specific antibody conjugated with Alexa fluorophores 488, 555, or 633 (1:500; Invitrogen). For Nissl staining, frozen sections were stained with $0.5 \%$ cresyl violet and revealed in $95 \%$ ethanol $/ 0.1 \%$ acetic acid. TUNEL staining was performed following manufacturer's protocol using ApopTag fluorescein in situ detection kit (Millipore). EdU staining was performed following the manufacturer's protocol using Click-iT EdU Alexa Fluor 488 imaging kit (Invitrogen). Immunofluorescent images were analyzed using a Leica DM6000 microscope or Zeiss Axiovert 200M microscope with LSM510 meta confocal system and processed with Volocity (PerkinElmer), PictureFrame (Optronics), and Adobe CS3 (Adobe Systems) software.

Statistical analysis. Coronal sections of the forebrain at three to four different levels along the rostral-caudal axis were carefully matched between control and mutant animals based on Nissl histological images. For quantification of cells expressing pHH3, BrdU, RFP, GFP, Cuxl, or Ctip2, a single optical section of confocal fluorescent microscope images were used to identify the cells expressing markers alone or in combination. A rectangular marquee with a fixed width spanning the entire cortical thickness was placed at a $45^{\circ}$ angle to the cortex to approximately mark the somatosensory cortex. Next, the cells expressing each marker were counted in separate channels in Adobe CS3 Photoshop; the number of cells was divided by the area of the section to account for differences in sample size. In cases where the quantification results are represented as number of cells per unit area, the area of the cortical section analyzed was measured using the measurement feature of Volocity (PerkinElmer). Quantification results are shown as indicated in graphs as a fraction of the total number of counted cells (see Figs. 1, $2 I, J, 5 D, E, 6 I, J$ ), a number per unit area (see Fig. 3E, 4I,J, 5F; supplemental Fig. S5E, available at www.jneurosci.org as supplemental material), or normalized value to the control (supplemental Fig. S4 I, available at www.jneurosci.org as supplemental material). All statistical analyses were done with Student's $t$ test; $p<0.05$ was considered statistically significant.

\section{Results}

Gli3 in neural progenitors is required for proper cortical lamination

To overcome the early patterning defect seen in $G l i 3^{X t / X t}$-null mice, we used Nestin-Cre (Tronche et al., 1999) and Gli3 ${ }^{F}$ (Blaess et al., 2008) mice to conditionally remove the Gli3 gene in neural tissue, including the dorsal telencephalon where Cre-mediated recombination results in the complete deletion of Gli3 by E14.5 (supplemental Fig. S1, available at www.jneurosci.org as supplemental material).

Since Gli3 is strongly expressed in the VZ of developing neocortex (supplemental Fig. S1, available at www.jneurosci.org as supplemental material) (Schimmang et al., 1992; Fotaki et al., 2006), we first examined whether the cortical progenitors lacking Gli3 generated cortical lamination according to temporal order (McConnell, 1991) in Nestin-Cre;Gli3 ${ }^{F / X t}$ conditional mutants (Gli3 ${ }^{\text {cko }}$ ). We performed a series of birthdating experiments with BrdU, a thymidine analog, to label cells in their last S-phase at the time of BrdU injection (Howell et al., 1997) at E11.5, E13.5, and E15.5. Embryos were collected and the final location of the BrdU+ cells was examined at E18.5, by which time distinct layers of neocortex are identifiable. The cells born at E11.5, before Gli3 deletion is complete in the forebrain of $\mathrm{Gli3}^{\text {cko }}$, were mostly distributed in deeper cortical layers, similar to control (Fig. 1 $A, B$ ). The majority of E13.5-born neurons were located in upper cortical layers in control neocortices. In contrast, BrdU+ cells were distributed more evenly throughout the cortex of Gli $^{\text {cko }}$, with significant presence of cells in the deeper cortical layers (Fig. 1C,D, brackets). Interestingly, we found that the E15.5born neurons exhibited an even more pronounced bias toward deeper cortical layers in their distribution than E13.5-born neurons did (Fig. $1 E, F$, brackets). To examine whether there was a delayed production of upper-layer cortical neurons in Gli3 ${ }^{\text {cko }}$, we injected BrdU at E18.5 and the brains were examined at P3. There were only few cells labeled with BrdU in controls and mutants, and Gli3 ${ }^{\text {cko }}$ did not display preferential position in upper cortical layers (supplemental Fig. S2, available at www.jneurosci.org as supplemental material). Since newborn neurons reach the appropriate cortical layers by migrating along the radial processes of RGCs, we next investigated whether the positional defects in our Gli3 ${ }^{\text {cko }}$ were due to the defective RGCs and found that the expression of Nestin and RC2, the markers for RGCs, were similar between controls and mutants (supplemental Fig. S3, available at www.jneurosci.org as supplemental material, and data not shown). These results indicate that Gli3 plays a critical role in determining the positional identity of cortical neurons generated from the progenitors.

\section{Loss of Gli3 prolongs production of deeper cortical neurons}

Next, we investigated whether the mispositioning of cortical neurons in Gli $^{\text {cko }}$ cortex was due to a change in cell fate by analyzing the molecular identity of cortical neurons born at specific embryonic stages. Upper-layer and deeper-layer cortical neurons can be identified by Cux1 and Ctip2, respectively (Molyneaux et al., 2007). As their locations indicated, neurons born at E11.5 were predominantly Ctip2+ deeper-layer cortical neurons in both controls $(65.0 \pm 7.4 \%)$ and mutants $(70.2 \pm 9.3 \%, N=3$ per genotype, $p>0.1)$, whereas hardly any neurons became upperlayer neurons $(\mathrm{Cux} 1+)$ in either case. However, there was a significant difference in molecular identity of cells born at E13.5 and at E15.5 (Fig. 2) when Gli3 is deleted in Gli3 ${ }^{\text {cko }}$. Although the cortical neurons born at E13.5 mostly became Cux1+ upperlayer neurons in controls, a smaller proportion of cells were Cux1+ in Gli3 ${ }^{\text {cko }}$ (Fig. 2A,B,I); this reduction in production of Cux1+ neurons was more apparent at E15.5 (Fig. 2C,D,J). 
Together, our results indicate that mispositioning of cortical neurons born at E13.5-E15.5 was not due to defective migration of correctly specified Cux $1+$ cortical neurons to the upper cortical layers, but rather a failure to get specified in the absence of Gli3. Interestingly, there was a persistent production of Ctip2+ deeper-layer neurons at E13.5 and at E15.5 in Gli3 ${ }^{\text {cko }}$ in contrast to the control cortex where almost no Ctip2+ cells were produced at these stages (Fig. $2 E-J)$. Together, our results suggest that the Gli3 mutant progenitors have a bias to produce deeper-layer cortical neurons at the expense of upper-layer neurons.

In addition, a majority of initially formed upper-layer cortical neurons lost Cux 1 expression, resulting in only small patches of Cuxl+ neurons in postnatal Gli3 $^{\text {cko }}$ cortex (Fig. 3F,G), possibly due to the selective apoptosis of upper-layer cortical neurons in postnatal Gli3 ${ }^{c k o}$ (Fig. 3C-E). We further verified the selective reduction in the upper cortical layers with additional layer markers such as Satb2 and Tbr1 in postnatal Gli3 ${ }^{\text {cko }}$ mutants (supplemental Fig. S4, available at www.jneurosci.org as supplemental material). Furthermore, we found that the corpus callosum, the major axonal tracts of upper layer callosal projection neurons, was also severely reduced, as demonstrated by Nissl and MBP staining (Fig. $3 H, I$ ), suggesting that postnatal loss of Cux1+ cells is partly responsible for this phenotype. Together, our results indicate that even though the reduced number of upper cortical neurons is generated from neural progenitors lacking Gli3 during development, they do not survive and mature properly to become callosal projection neurons.

IPCs are gradually lost in the absence of Gli3 due to decreased proliferation of RGCs and premature cell cycle exit

Since upper-layer cortical neurons are generated via IPCs rather than directly from RGCs (Sessa et al., 2008), we investigated whether there is any change in maintenance and proliferation of the IPCs identified by Tbr2 expression (Englund et al., 2005) in Gli3 ${ }^{\text {cko }}$ that could account for observed defects in cortical lamination. We noticed that there was a gradual loss of Tbr2-expressing IPCs in Gli3 ${ }^{\text {cko }}$ by E18.5 (Fig. 4A-D,I). Three possibilities that could result in depletion of IPCs in Gli3 ${ }^{\text {cko }}$ are reduced production of IPCs from RGCs, increased apoptosis of IPCs, and premature differentiation of IPCs.

First, we examined the extent of apoptosis and found that there was no significant increase in cell death at E16.5 and only slight increase at E18.5 in Gli3 ${ }^{\text {cko }}$, suggesting that cell death is
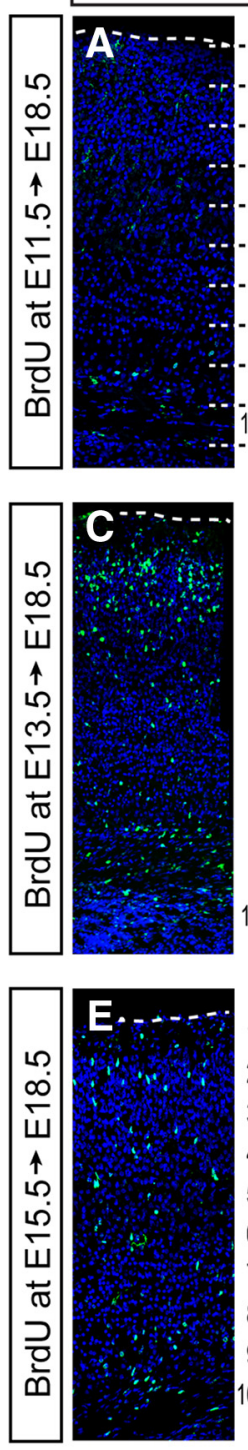
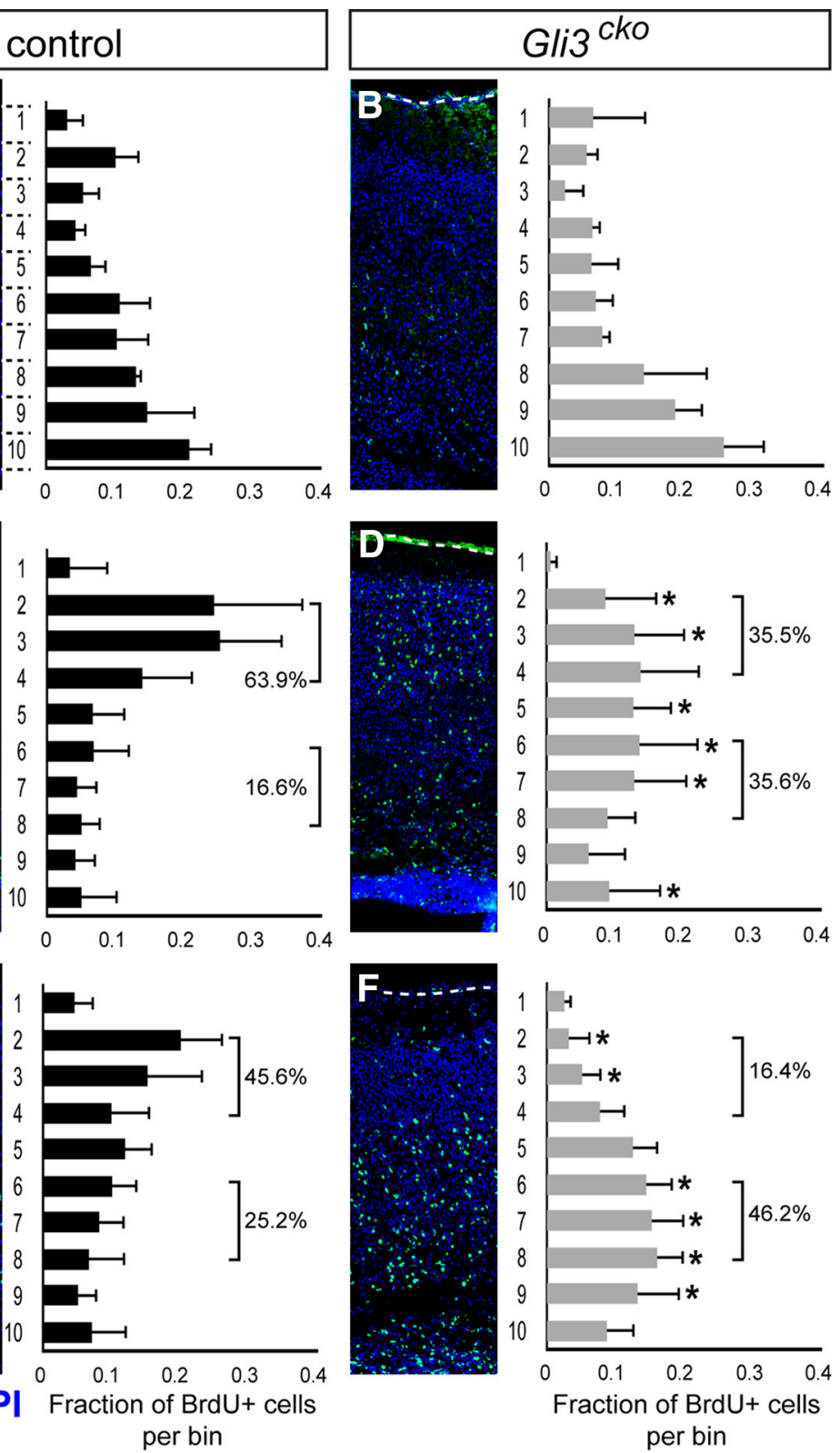

Figure 1. Loss of Gli3 results in aberrant positioning of cortical neurons. BrdU was injected to label cells born at the indicated embryonic stages and analyzed at E18.5. A-F, Representative immunofluorescent images for BrdU (green) and distribution of $\mathrm{BrdU}+$ cells in 10 bins spanning the cortical thickness are shown as histograms. Although E11.5-born cells show similar distribution in both controls $(\boldsymbol{A})$ and Gliz $^{\text {cko }}(\boldsymbol{B})$, greater fractions of cells born at E13.5 $(\boldsymbol{D})$ and E15.5 $(\boldsymbol{F})$ are found in deeper cortical layers compared with respective controls $(\boldsymbol{C}, \boldsymbol{E})$. Percentage of cells in upper layers (bins $2-4$ ) and deeper layers (bins $6-8$ ) are indicated in the histograms. $N=3$ per genotype per experimental condition, except $N=5$ for BrdU injection at E13.5 in Gli3 ${ }^{c k o} .{ }^{*} p<0.001$. Controls are Nestin-Cre;Gli3F/+ and Gliz ${ }^{\text {cko }}$ are Nestin-Cre; Gli3 ${ }^{F / x t}$. Error bars represent the SD.

unlikely to be a major contributing factor to the loss of IPCs (Fig. $3 A, B, E)$. Next, we quantified the mitotic progenitors labeled with antibody against $\mathrm{pHH} 3$ based on their location: the RGCs in the apical VZ (labeled with Pax6) and IPCs in the basal SVZ. We found that the number of mitotic RGCs was similar in both Gli3 ${ }^{\text {cko }}$ and controls at E12.5 (supplemental Fig. S5, available at www.jneurosci.org as supplemental material) and at E14.5 (Fig. $4 E, F, J)$. However, the mitotic rate of RGCs in Gliz ${ }^{\text {cko }}$ gradually decreased to $72.9 \%$ of controls at E16.5 and only $57.6 \%$ of controls at E18.5 (Fig. $4 G, H, J$ ), indicating the decreased IPCs could result from reduced mitotic division of RGCs.

Interestingly, the number of mitotic IPCs was transiently increased in Gli3 ${ }^{\text {cko }}$ compared with controls at E14.5 but not at 

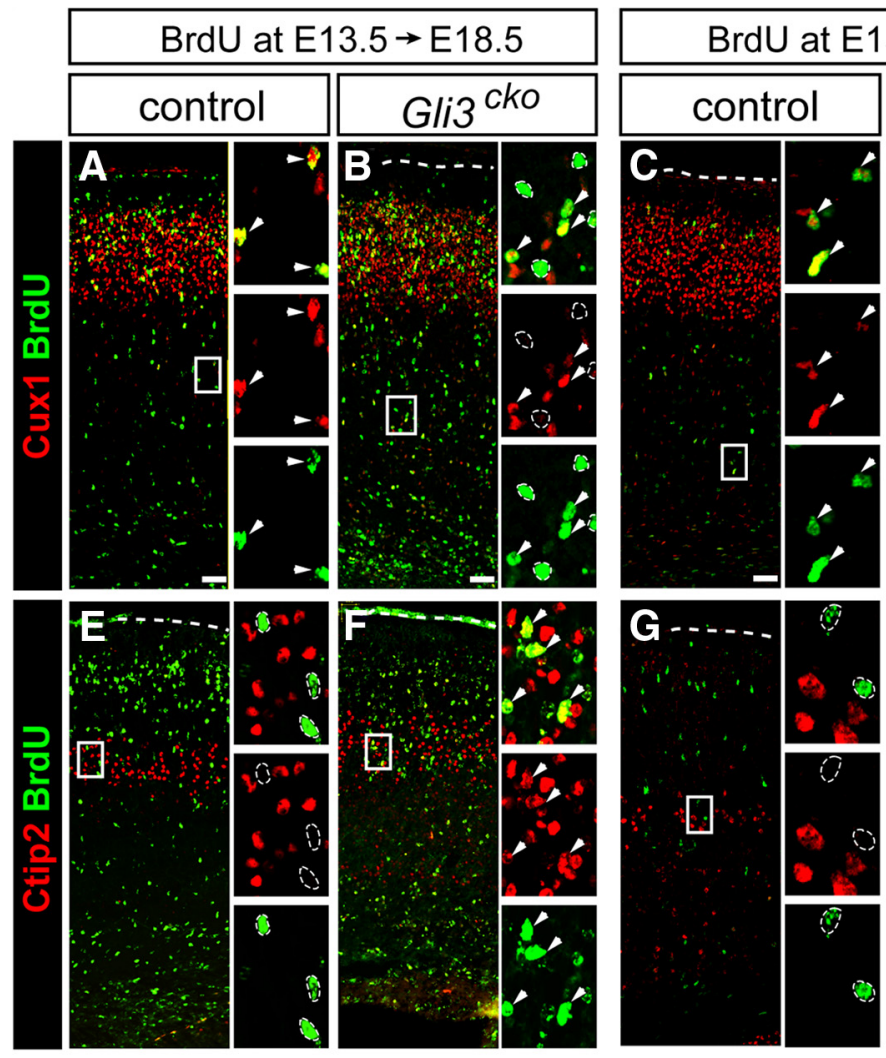

Gli3 $^{\text {cko }}$

thymidine analog $+\mathrm{Ki} 67-$ cells to the total number of thymidine analog + cells indicates the proportion of cells that have left the cell cycle (Chenn and Walsh, 2002). We found that a greater portion of mutant cells $(77.8 \pm 8.9 \%)$ that were mitotic at E14.5 became postmitotic by E15.5 compared with the controls (60.0 \pm $7.4 \%, p=0.00008, N=3$ per genotype) (Fig. $5 D$, green). There was also a significant increase in cells mitotic at E14.5 exiting cell cycle by E16.5 in Gli3 ${ }^{\text {cko }}$ (8.7 \pm $3.5 \%$ ) compared with the control (4.43 \pm $1.6 \%, p=0.002, N=3$ per genotype) (Fig. 5D, blue). This increased cell cycle exit was also observed among cells that were dividing at E15.5 in Gli3 ${ }^{\text {cko }}$ compared with the controls (Fig. $5 E$ ). Moreover, we found that the majority of dividing cells at E14.5 were located in the developing cortical plate (CP) by E16.5 in Gli3 $^{\text {cko }}$, unlike in controls where most cells remained in the SVZ and VZ (Fig. $5 A, B, F)$. Together, our results indicate that the ectopically dividing cells observed at E14.5 did not result in the increased number of IPCs but rather accelerated the premature cell cycle exit of IPCs that led to the depletion of IPCs in Gliz ${ }^{c k o}$ and the eventual loss of the IPC-generated upperlayer cortical neurons.

\section{Repressor form of Gli3 is responsible} for cell-autonomous function of Gli3 in cortical development

To address the cell-autonomous requirement of Gli3, we used in utero electroporation technique to create Gli3 mutant cells in a wild-type environment. E13.5 embryos with Gli3 $^{F / F} ;$ ROSA $26^{R / R}$ alleles were electroporated with fluorescent reporter constructs (RFP or GFP) with or without Cre recombinase and brains were collected at E18.5. We verified Cremediated recombination in electroporated cells by the lac $Z$ expression from ROSA26 $6^{R / R}$ allele (supplemental Fig. S6, available at www.jneurosci.org as supple-

Figure 2. Production of deeper-layer cortical neurons persists at the expense of upper-layer cortical neurons in $\mathrm{Gli3}^{\mathrm{cko}} . \mathbf{A}-\boldsymbol{H}$, Cells labeled with BrdU at E13.5 or E15.5 were analyzed for their neuronal identity at E18.5 using Cux1 (A-D) or Ctip2 $(\boldsymbol{E}-\boldsymbol{H})$ as markers for upper- and deeper-layer cortical neurons, respectively. White boxed areas are shown at higher magnification (right) to show the cells coexpressing BrdU and indicated markers (arrowheads) or only BrdU (dashed outline). Scale bars, $50 \mu \mathrm{m} . I, J$ Quantification of BrdU + cells show that there is persistent production of Ctip2 + neurons in Gli3 ${ }^{\text {cko }}$ atE13.5 (I) and E15.5 (J). Error bars represent the SD.

E18.5 (Fig. 4E, F,J). Although this burst in mitotic activity of IPCs initially increased the number of IPCs at E14.5, it failed to sustain the size of IPC pool (Fig. 4I). Thus, we asked whether dividing IPCs remain in active cell cycle or become postmitotic prematurely in Gli3 ${ }^{\text {cko }}$. We injected the thymidine analogs EdU and BrdU at E14.5 and E15.5, respectively, to label cells in the S-phase of cell cycle at the time of injections and analyzed the status of cell cycle at E16.5 (Fig. 5). Since Ki67 labels the cells in active cell cycle at the time of analysis, expression of Ki67 within cells that took up the thymidine analogs indicate the cells remaining in active cell cycle from the time of injection to the analysis. Specifically, the cells remaining in cell cycle from E14.5-E16.5 will be EdU+ $\mathrm{BrdU}+\mathrm{Ki} 67+$, whereas cells that have exited cell cycle by E15.5 and E16.5 will be EdU + BrdU- Ki67 - and EdU+ BrdU+ Ki67-, respectively (Fig. 5C). Thus, the ratio of the number of mental material) and assumed these cells as Gli3 mutant cells. Control electroporated cells behaved as expected for cells born at E13.5 (Fig. 1) by becoming upper-layer cortical neurons, as indicated by their location and Cuxl expression (Fig. 6A,E) and did not become Ctip2 + deeper-layer cortical neurons (only three Ctip2 + RFP + cells among $411 \mathrm{RFP}+$ cells counted in five animals) (Fig. 6C, $G$ ). In contrast, cells expressing Cre, thus lacking Gli3, were scattered throughout the cortex (Fig. 6B,D), recapitulating the phenotype of E13.5-born cells of Gli3 ${ }^{\text {cko }}$ cortex (Fig. 1). Moreover, Cre-expressing cells became less of Cux1 + cells (Fig. 6B,I) and more of Ctip2 + cells (Fig. 6D,J), as in Gli3 ${ }^{\text {cko }}$ cortex, confirming the cell-autonomous requirement of Gli3 in cortical neurogenesis.

Since Gli3 acts as either a transcriptional repressor or an activator in the context of Shh signaling through posttranslational 


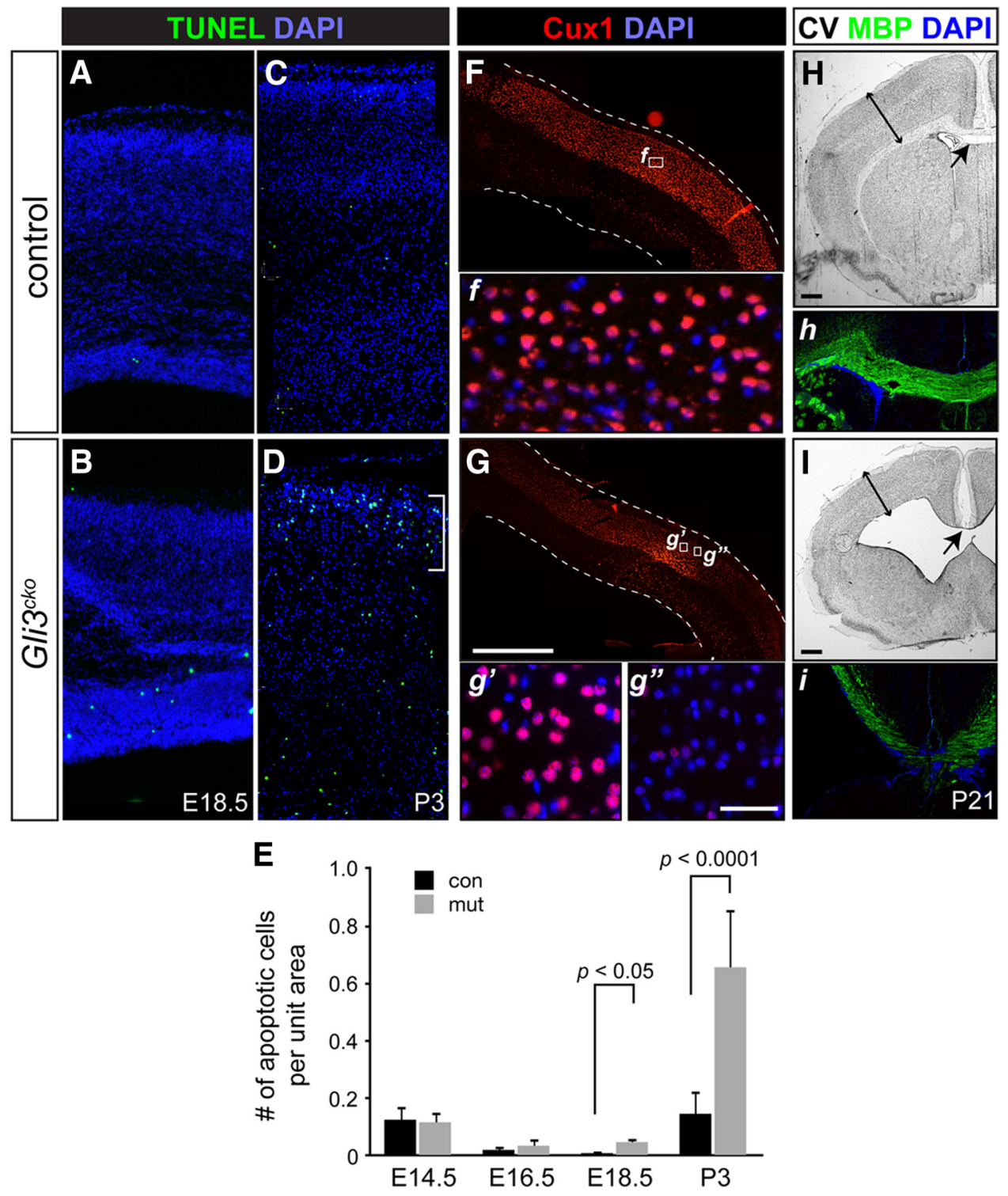

Figure 3. Loss of Cux1-expressing upper-layer cortical neurons in postnatal Gliz ${ }^{\text {cko }}$ cortex. $A-D$, TUNEL assay on E18.5 $(\boldsymbol{A}, \boldsymbol{B})$ and P3 $(\boldsymbol{C}, \boldsymbol{D})$ brains show more apoptotic cells (green), especially in upper cortical layers of $\mathrm{Gli3}{ }^{\text {cko }}$ brain $\left(\boldsymbol{D}\right.$, bracket). $\boldsymbol{E}$, The number of apoptotic cells per unit area shows that an increase in cell death does not occur in $G / i^{c^{c k o}}$ cortex until E18.5 and is greatly increased at P3. N = 3 per genotype. $\boldsymbol{F}, \mathbf{G}$, Lower-magnification images of Cux1 immunostaining show very weak Cux1 immunoreactivity in most of the upper cortical layers in the P21 Glij ${ }^{\text {cko }}$ brain (G) in contrast with the strong uniform Cux 1 expression $(\boldsymbol{F})$. Within the mutant cortex, patches of Cux $1+$ cells with bigger nuclei $(\boldsymbol{g})$ are found adjacent to the areas with low Cux 1 immunoreactivity and smaller nuclei $\left(\boldsymbol{g}^{\prime \prime}\right)$. Scale bars: $\boldsymbol{F}, \boldsymbol{G}$ (in $\left.\boldsymbol{G}\right), 1 \mathrm{~mm} ; \boldsymbol{g}^{\prime}, \boldsymbol{g}^{\prime \prime}$ (in $\left.\boldsymbol{g}^{\prime \prime}\right), 20 \mu \mathrm{m}$. $\boldsymbol{H}, \boldsymbol{I}$, Nissl staining of P21 Gli3 ${ }^{\text {cko }}$ brain shows reduced cortical thickness (double-headed arrows), reduced corpus callosum (single-headed arrows), and larger lateral ventricle compared with the control. Axonal projections in the presumptive corpus callosum was also greatly reduced in Glij ${ }^{\text {cko }}$ brain, as indicated by MBP staining $(\boldsymbol{h}, \boldsymbol{i})$. Error bars represent the SD.

processing (Wang et al., 2000), we next asked which form of Gli3 mediates its regulatory role in neural progenitors. It is likely that Gli3 exists as a repressor form (Gli3R) in developing neocortex since Shh activity is localized to the ventral forebrain (Tole et al., 2000; Hébert and Fishell, 2008) even though the requirement of Shh signaling was reported in the dorsal cortex (Komada et al., 2008). When Gli3R was coexpressed with Cre at E13.5, electroporated cells behaved like the control cells born at E13.5 by becoming the upper-layer cortical neurons in their location and Cux1 expression (Fig. 6F,I). In addition, the ectopic production of Ctip $2+$ cells in the absence of Gli3 was reversed and we found only two Ctip $2+$ electroporated cells among 879 cells counted in seven animals (Fig. $6 \mathrm{H}, \mathrm{J}$ ). Together, our data demonstrate that Gli3 in the form of repressor is intrinsically required for fate specification of cortical neurons, especially those in the upper layers (Fig. 7).

\section{Discussion}

Shh-positive signaling induces mitogenic responses in the developing cerebellum and in adult neural stem cells (Wechsler-Reya and Scott, 1999; Ahn and Joyner, 2005). As a negative effector of the pathway, Gli3 may simply act opposite of Shh by blocking proliferation in dorsal telencephalon where $S h h$ is not expressed and an increased proliferation would be expected upon the removal of Gli3 (Gli3R in dorsal cortex). In our Gli3 ${ }^{\text {cko }}$ mutant, we indeed observed a transient increase in mitotic activity in the SVZ at E14.5 when Gli3 deletion was complete. These results suggest that Gli3 is not a simple repressor of proliferation in the develop- 


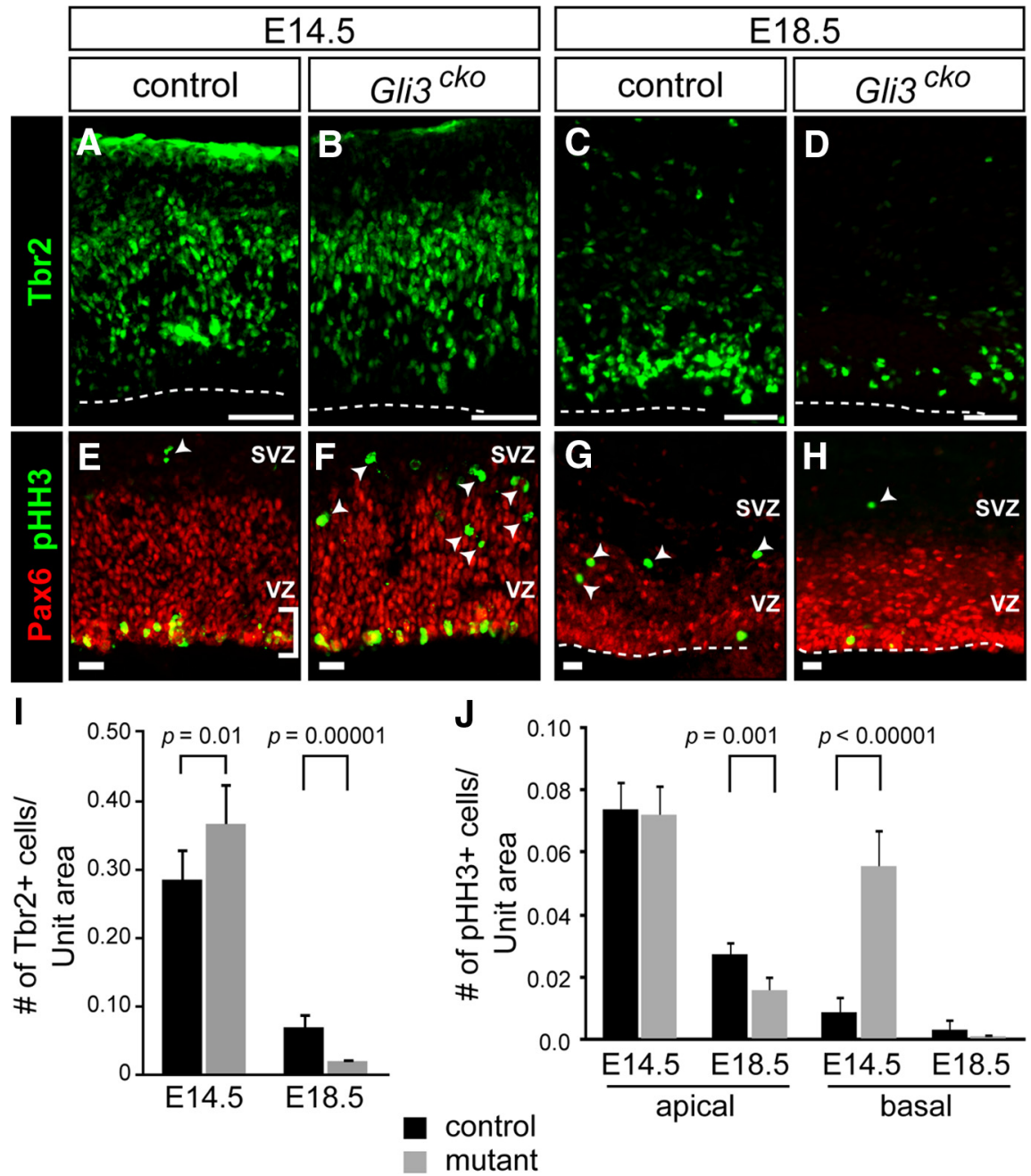

Figure 4. IPCs are gradually depleted in Gli3 $3^{\text {cko }}$. A-D, Tbr2-expressing IPCs (green) are greatly reduced in Gli3 ${ }^{\text {cko }}$ at E18.5 (D). $N=3$ at E14.5 and $N=4$ at E18.5, per genotype. $\boldsymbol{E}-\boldsymbol{H}$, Mitotic cells are labeled with antibody against $\mathrm{pHH} 3$ (green) and the VZ is identified with Pax6 expression (red). Note the pHH3 + cells in the basal VZ and SVZ (arrowheads) at E14.5 Gli3 ${ }^{\text {cko }}(\boldsymbol{F}) . \boldsymbol{I}$, Quantification of Tbr2 + IPCs shows a slight increase at E14.5 followed by a great reduction at E18.5 in the mutants compared with the controls. J, Quantification of pHH3 + cells based on their location (I) shows that more IPCs are dividing at E14.5 in Gliz ${ }^{\text {cko }}$ (basal pHH3 +) and the number of mitotic RGCs in the mutants is less than controls at E18.5 (apical pHH3 +; bracket). Scale bars: $\mathbf{A - D}$, $50 \mu \mathrm{m} ; \boldsymbol{E}-\boldsymbol{H}, 20 \mu \mathrm{m}$. Error bars represent the SD.

ing neocortex. The expression level of Gli3 protein would be highest in the VZ, as deduced from the expression pattern of Gli3 transcripts (supplemental Fig. S1, available at www.jneurosci.org as supplemental material) (Schimmang et al., 1992; Fotaki et al., 2006). Thus, we can postulate that the level of Gli3 protein would decrease as cells transit from the RGCs in the VZ to the IPCs in the SVZ and then to postmitotic neurons in the CP, as dictated by the stability of Gli3 protein, posing the possibility that this reduction in Gli3 protein level may trigger cells to exit the cell cycle sooner to acquire a more differentiated state and lose progenitor characteristics. In support of this theory, the increased mitotic activity of IPCs seen in Gli3 ${ }^{c k o}$ was not to keep them in active cell cycle (more progenitor state) but was accelerating the premature differentiation to deplete the progenitor pool (Fig. 5). A previous report that embryonic cortical cells from $\mathrm{Gli}^{\mathrm{Xt} / \mathrm{Xt}}$ mice fail to generate neurospheres and the few surviving Gli3 mutant cells spontaneously differentiate into $\mathrm{TuJ} 1+$ neurons (Palma and Ruiz i Altaba, 2004) further supports the idea that a gradual reduction or absence of Gli3 may be a key determinant step for the IPCs to become postmitotic.
Although Shh activity is not reflected by Gli1 transcription in the developing cortex (Hui et al., 1994; Tole et al., 2000; Rallu et al., 2002; Palma and Ruiz i Altaba, 2004), Shh-positive signaling is still required for proper regulation of cortical progenitors in the developing cortex (Komada et al., 2008). A very low level of Shh signaling, which is not sufficient to induce transcriptional response, may be capable of regulating the processing of Gli3 protein and consequently affecting the ratio between Gli activators (Gli2 and Gli3A) and repressor (Gli3R). Our results show that neural progenitors exit cell cycle prematurely in Gli3 ${ }^{\text {cko }}$ (Fig. 5) and the Gli3Roverexpressing cells remain in the $\mathrm{Ki} 67+$ progenitor domain (supplemental Fig. S7, available at www.jneurosci. org as supplemental material). Consistent with our theory that Gli3R is responsible for maintaining the IPCs in active cell cycle, the neural progenitors in Shh and Smo conditional mutants remain in cell cycle longer (Komada et al., 2008), possibly due to the increased level of Gli3R.

In addition to the newly discovered role of Gli3 in cell cycle regulation, we demonstrate that Gli3R is critical in determining the fate of cortical neurons produced. Both birthdating and in utero electroporation experiments indicate that Gli3 mutant progenitors lacking Gli3(R) ectopically produce neurons with deeper cortical layer identity at the expense of neurons in the upper layers. Since cortical neurogenesis follows a temporal order of generating deeper-layer neurons earlier than upper-layer neurons, this phenotype could be caused by developmental delay in Gli3 $^{\text {cko }}$. However, our findings that Gli3 $^{\text {cko }}$ mutants produce deeper-layer cortical neurons through E15.5 and even slightly at E18.5 argue against a developmental delay. Furthermore, the fact that we were able to not only rescue the phenotype of Gli3 mutant cells with Gli3R but also suppress the production of deeper layer neurons at a statistically significant level strongly suggests that Gli3R is the major player governing the fate of cortical progenitors.

Even though there are more selective defects in upper-layer cortical neurons in our Gli3 ${ }^{c k o}$ mutants, Cux $1+$ upper cortical layers still form during development, albeit to a lesser extent. We believe that this is due to the mosaic nature of a conditional deletion system that generates heterogenous population of neural progenitors. Nestin promoter (Englund et al., 2005) drives Cre activity in the RGCs but not in the IPCs starting at approximately E12.5 in developing neocortex and it takes $\sim 30 \mathrm{~h}$ to complete three cell cycles from E12.5 (Takahashi et al., 1995; Salomoni and Calegari, 2010). Thus, IPCs generated from RGCs before E12.5 are likely to behave as wild-type IPCs for one or two more rounds of cell cycle until approximately E14 to produce wild-type upperlayer cortical neurons at later stages. Therefore, cortical neurons 

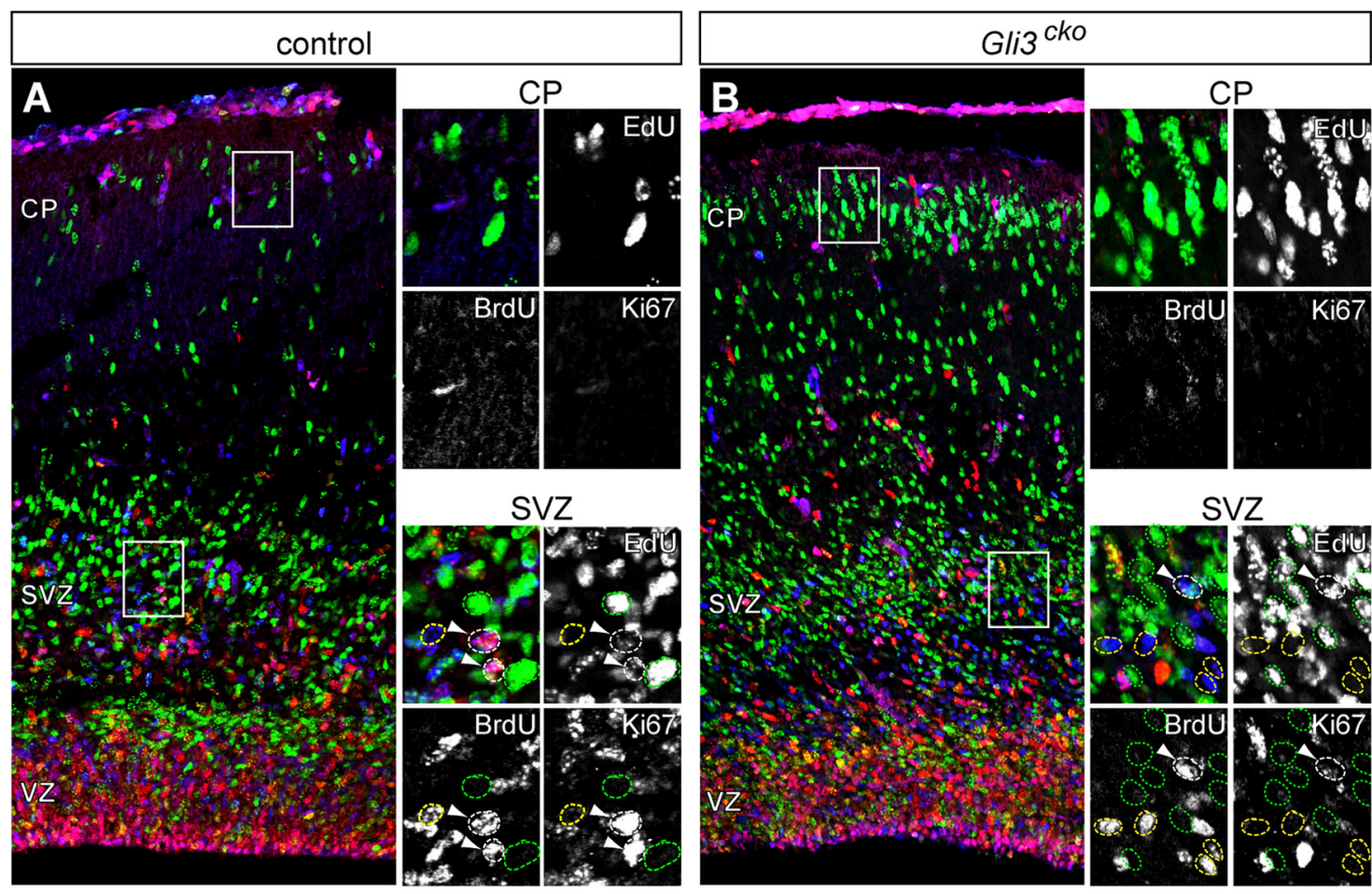

C
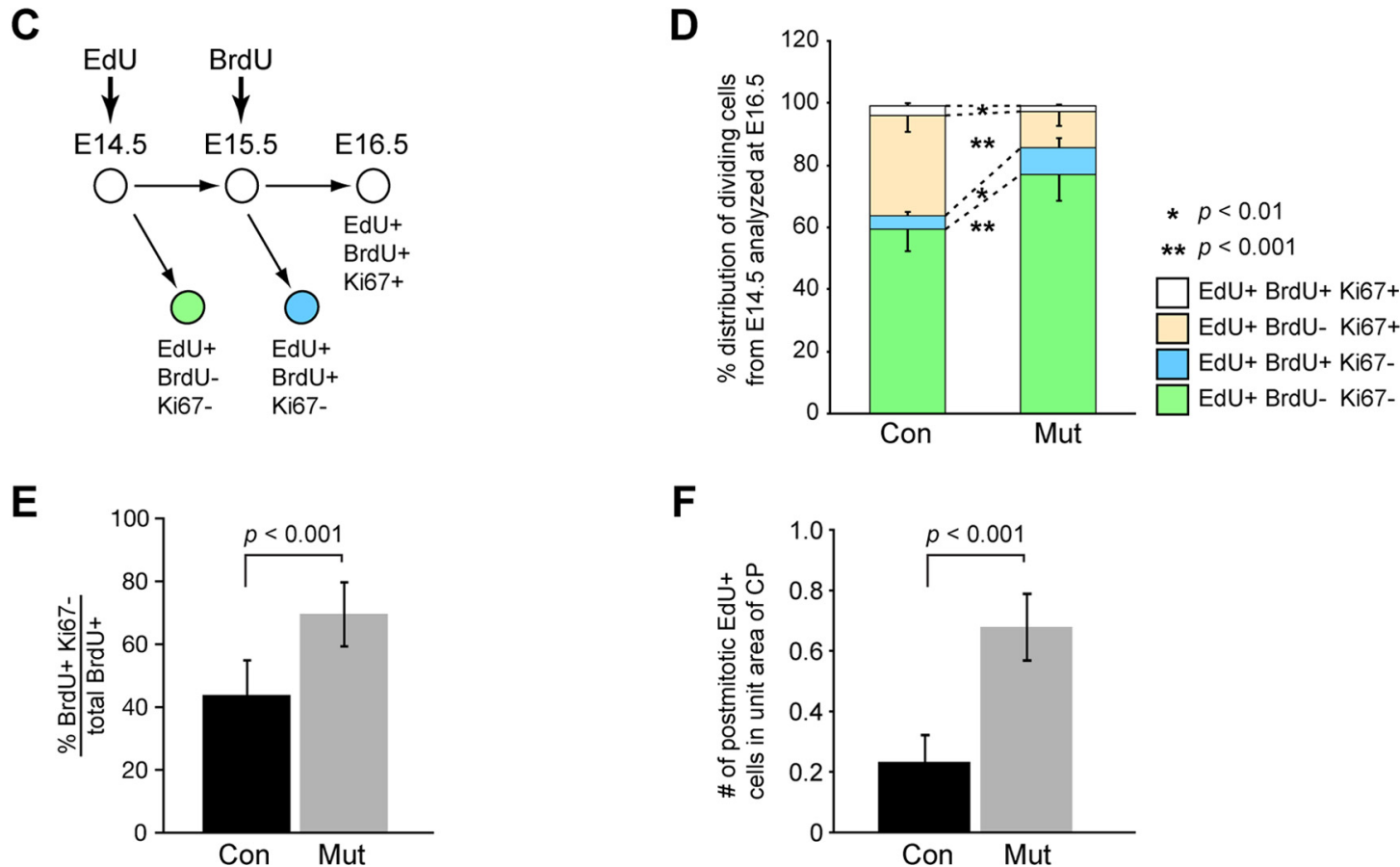

$\mathbf{F}$

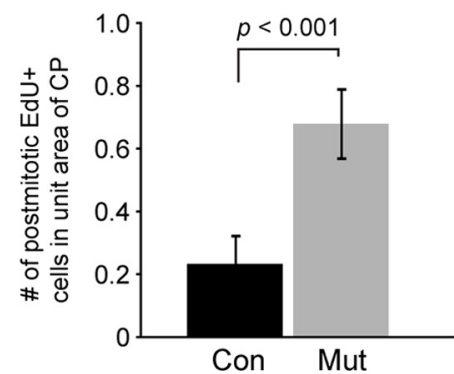

Figure 5. IPCs exit cell cycle prematurely in the absence of Gli3.A-C, Cell cycle exit was studied by labeling cells in the S-phase of cell cycle with EdU and BrdU at E14.5 and E15.5, respectively, and analyzed for coexpression of EdU (green), BrdU (blue), and Ki67 (red) at E16.5. Boxed areas of (P and SVZ are shown at higher magnification (right) to indicate cells remaining in cell cycle from E14.5 to E16.5 (EdU + BrdU + Ki67 +, white dashed outline and arrowheads), cells that exited cell cycle by E15.5 (EdU + BrdU - Ki67 - , green dashed outline), and cells that exited cell cycle by E16.5 (BrdU + Ki67-, yellow dashed outline). Note that more EdU + cells are found in the CP in Gliz ${ }^{\text {cko }}$ than in controls. D, Cells that were dividing at E14.5 (EdU +) were quantitatively analyzed at E16.5 for their cell cycle status. A higher percentage of EdU + became postmitotic by E15.5 (EdU + BrdU - Ki67 -, green) in Gli3 ${ }^{\text {cko }}$ than in controls (Con). Similarly, more mutant (Mut) cells exited cell cycle by E16.5 (EdU + BrdU + Ki67 - , blue) compared with controls. In contrast, there was a decrease in the number of EdU + cells remaining in cell cycle by E16.5 (EdU + BrdU - Ki67 +, yellow; $\mathrm{EdU}+\mathrm{BrdU}+\mathrm{Ki} 67+$, white). $\boldsymbol{E}$, Cells dividing at E15.5 (BrdU+) also increased the cell cycle exit by E16.5, as evidenced by the ratio of BrdU + Ki67 - cells to the total number of BrdU + cells. $\boldsymbol{F}$, More EdU + cells were found to be postmitotic in the CP of Glij ${ }^{\text {cko }}$ compared with the control. $N=3$ per genotype for E14.5-dividing cell analysis. $N=8$ per genotype for E15.5-dividing cell analysis. Error bars represent the SD.

born at E13.5 could be generated from a mixed population of wild-type and mutant IPCs and become upper-layer cortical neurons. The fact that the positional bias is more pronounced among E15.5-born neurons in $\mathrm{Gli3}^{\text {cko }}$, which are likely descendants of more Gli3 mutant IPCs than E13.5-born neurons, further supports the importance of Gli3 in fate determination of cortical neurons. In addition, postnatal loss of Cux $1+$ upper-layer cortical neurons suggests the events downstream of Gli3 progenitors 

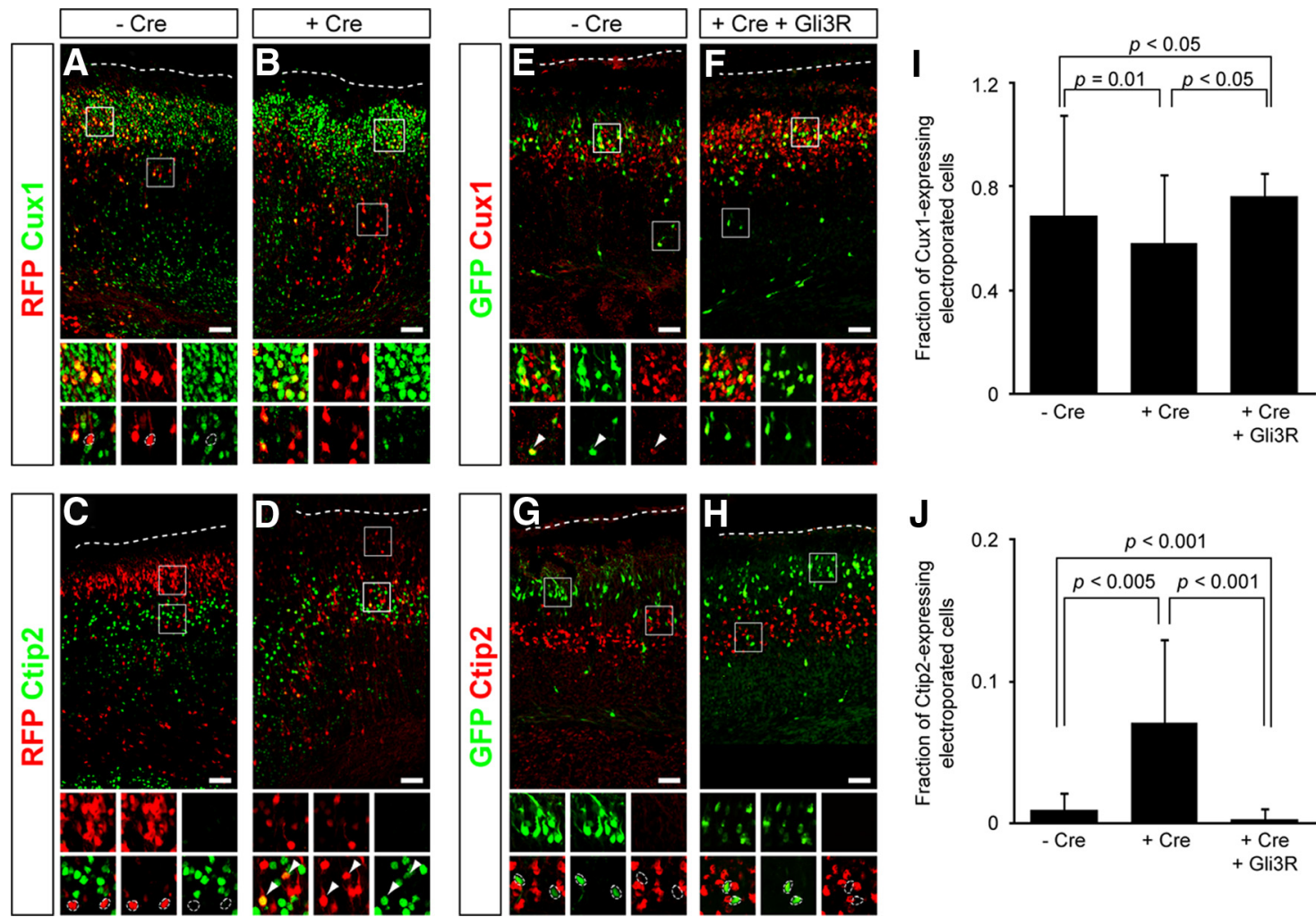

Figure 6. Gli3R is responsible for the proper positioning and fate specification of cortical neurons. $\boldsymbol{A}-\boldsymbol{H}, \mathrm{E} 13.5 \mathrm{Gli3}{ }^{F / F} ; R 0 \mathrm{SA} 6^{R / R}$ embryos were electroporated in utero with indicated DNA constructs and analyzed at E18.5. Control cells electroporated with $\operatorname{pRFP}(\boldsymbol{A}, \boldsymbol{C})$ or $\operatorname{pGFP}(\boldsymbol{E}, \boldsymbol{G})$ were mostly found in the upper cortical layers expressing Cux $1(\boldsymbol{A}, \boldsymbol{E})$ and were rarely found in deeper layers expressing Ctip2 (C, G). In contrast, cells coelectroporated with Cre plasmid showed scattered distribution throughout the cortex $(\boldsymbol{B}, \boldsymbol{D})$ and were more likely to express $(\mathrm{Ctip2}(\boldsymbol{D})$. Introduction of Gli3R construct in Cre-expressing cells reversed this phenotype by becoming more similar to control electroporated cells in their location in upper cortical layers $(\boldsymbol{F}, \boldsymbol{H})$ and expression of Cux $1(\boldsymbol{F})$ but not Ctip2 $(\boldsymbol{H})$. Higher-magnification images of boxed areas of both upper and deeper cortical layers are shown underneath each experimental condition. Dotted circles highlight the single positive cells; arrowheads indicate double-positive cells. $N=5$ for $-\mathrm{Cre}, 4 \mathrm{for}+\mathrm{Cre}$, and 7 for + Cre + Gli3R. Scale bars, $50 \mu \mathrm{m}$. I, J, Quantification of the electroporated cells (identified by RFP or GFP expression) shows that Cre-expressing Gli3 mutant cells express less Cux1 ( $p=0.01$ ) and more Ctip2 ( $p=0.005$ ) compared with controls ( - Cre). However, Gli3R can rescue the phenotype of Cre-expressing mutant cells by converting to Cux1 + cells $(p<0.05)$ and rarely becoming Ctip2 + cells $(p<0.001)$ as in control cells. In addition, overexpression of Gli3R reversed the mutant phenotype by generating more Cux $1+$ cells $(p<0.05)$ and suppressing Ctip $2+$ cells $(p<0.001)$ compared with the controls $(-$ Cre). Error bars represent the SD.

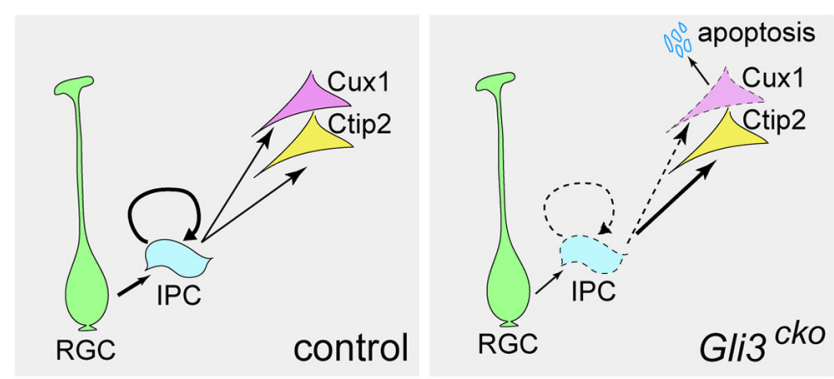

Figure 7. Schematic diagram of cortical development shows that the loss of Gli3 in RGC results in decreased production of $\mathrm{IPC}$, which further deplete themselves via increased cell cycle exit. In addition, the cortical neurons generated from mutant IPCs adopt Ctip2 + deeper cortical neuron identity at the expense of Cux1 + upper cortical neurons, which also exhibit abnormalities in their survival and maturation.

may be required for proper maintenance and full maturation of Cux $1+$ upper-layer cortical neurons.

In summary, we provide evidence for a novel function of Gli3 apart from its earlier role in $\mathrm{D} / \mathrm{V}$ patterning using conditional genetic ablation approaches. Our results demonstrate that Gli3 is required for both the generation and maintenance of IPCs and is involved in fate specification of IPC-generated cortical neurons. Future investigation of Gli3 function in other neural progenitors such as adult neural stem cells in their cell cycle regulation and differentiation would further enhance our understanding of Shh signaling pathway in neurogenesis.

\section{References}

Ahn S, Joyner AL (2005) In vivo analysis of quiescent adult neural stem cells responding to Sonic hedgehog. Nature 437:894-897.

Blaess S, Stephen D, Joyner AL (2008) Gli3 coordinates three-dimensional patterning and growth of the tectum and cerebellum by integrating Shh and Fgf8 signaling. Development 135:2093-2103.

Chenn A, Walsh CA (2002) Regulation of cerebral cortical size by control of cell cycle exit in neural precursors. Science 297:365-369.

Englund C, Fink A, Lau C, Pham D, Daza RA, Bulfone A, Kowalczyk T, Hevner RF (2005) Pax6, Tbr2, and Tbr1 are expressed sequentially by radial glia, intermediate progenitor cells, and postmitotic neurons in developing neocortex. J Neurosci 25:247-251.

Fotaki V, Yu T, Zaki PA, Mason JO, Price DJ (2006) Abnormal positioning of diencephalic cell types in neocortical tissue in the dorsal telencephalon of mice lacking functional Gli3. J Neurosci 26:9282-9292.

Friedrichs M, Larralde O, Skutella T, Theil T (2008) Lamination of the cerebral cortex is disturbed in Gli3 mutant mice. Dev Biol 318:203-214.

Fuccillo M, Joyner AL, Fishell G (2006) Morphogen to mitogen: the multiple roles of hedgehog signalling in vertebrate neural development. Nat Rev Neurosci 7:772-783.

Gal JS, Morozov YM, Ayoub AE, Chatterjee M, Rakic P, Haydar TF (2006) Molecular and morphological heterogeneity of neural precursors in the mouse neocortical proliferative zones. J Neurosci 26:1045-1056.

Götz M, Huttner WB (2005) The cell biology of neurogenesis. Nat Rev Mol Cell Biol 6:777-788.

Hébert JM, Fishell G (2008) The genetics of early telencephalon patterning: some assembly required. Nat Rev Neurosci 9:678-685. 
Hoch RV, Rubenstein JL, Pleasure S (2009) Genes and signaling events that establish regional patterning of the mammalian forebrain. Semin Cell Dev Biol 20:378-386.

Howell BW, Hawkes R, Soriano P, Cooper JA (1997) Neuronal position in the developing brain is regulated by mouse disabled-1. Nature 389:733-737.

Hui CC, Joyner AL (1993) A mouse model of greig cephalopolysyndactyly syndrome: the extra-toesJ mutation contains an intragenic deletion of the Gli3 gene. Nat Genet 3:241-246.

Hui CC, Slusarski D, Platt KA, Holmgren R, Joyner AL (1994) Expression of three mouse homologs of the Drosophila segment polarity gene cubitus interruptus, Gli, Gli-2, and Gli-3, in ectoderm- and mesoderm-derived tissues suggests multiple roles during postimplantation development. Dev Biol 162:402-413.

Komada M, Saitsu H, Kinboshi M, Miura T, Shiota K, Ishibashi M (2008) Hedgehog signaling is involved in development of the neocortex. Development 135:2717-2727.

Kriegstein A, Alvarez-Buylla A (2009) The glial nature of embryonic and adult neural stem cells. Annu Rev Neurosci 32:149-184.

McConnell SK (1991) The generation of neuronal diversity in the central nervous system. Annu Rev Neurosci 14:269-300.

Megason SG, McMahon AP (2002) A mitogen gradient of dorsal midline Wnts organizes growth in the CNS. Development 129:2087-2098.

Molyneaux BJ, Arlotta P, Menezes JR, Macklis JD (2007) Neuronal subtype specification in the cerebral cortex. Nat Rev Neurosci 8:427-437.

Noctor SC, Martínez-Cerdeño V, Ivic L, Kriegstein AR (2004) Cortical neurons arise in symmetric and asymmetric division zones and migrate through specific phases. Nat Neurosci 7:136-144.

Palma V, Ruiz i Altaba A (2004) Hedgehog-GLI signaling regulates the behavior of cells with stem cell properties in the developing neocortex. Development 131:337-345.

Rallu M, Machold R, Gaiano N, Corbin JG, McMahon AP, Fishell G (2002) Dorsoventral patterning is established in the telencephalon of mutants lacking both Gli3 and Hedgehog signaling. Development 129:4963-4974.
Salomoni P, Calegari F (2010) Cell cycle control of mammalian neural stem cells: putting a speed limit on G1. Trends Cell Biol 20:233-243.

Schimmang T, Lemaistre M, Vortkamp A, Rüther U (1992) Expression of the zinc finger gene Gli3 is affected in the morphogenetic mouse mutant extra-toes (Xt). Development 116:799-804.

Sessa A, Mao CA, Hadjantonakis AK, Klein WH, Broccoli V (2008) Tbr2 directs conversion of radial glia into basal precursors and guides neuronal amplification by indirect neurogenesis in the developing neocortex. Neuron 60:56-69.

Soriano P (1999) Generalized lacZ expression with the ROSA26 Cre reporter strain. Nat Genet 21:70-71.

Takahashi T, Nowakowski RS, Caviness VS Jr (1995) The cell cycle of the pseudostratified ventricular epithelium of the embryonic murine cerebral wall. J Neurosci 15:6046-6057.

Theil T, Alvarez-Bolado G, Walter A, Rüther U (1999) Gli3 is required for Emx gene expression during dorsal telencephalon development. Development 126:3561-3571.

Tole S, Ragsdale CW, Grove EA (2000) Dorsoventral patterning of the telencephalon is disrupted in the mouse mutant extra-toes(J). Dev Biol 217:254-265.

Tronche F, Kellendonk C, Kretz O, Gass P, Anlag K, Orban PC, Bock R, Klein R, Schütz G (1999) Disruption of the glucocorticoid receptor gene in the nervous system results in reduced anxiety. Nat Genet 23:99-103.

Wang B, Fallon JF, Beachy PA (2000) Hedgehog-regulated processing of Gli3 produces an anterior/posterior repressor gradient in the developing vertebrate limb. Cell 100:423-434.

Wechsler-Reya RJ, Scott MP (1999) Control of neuronal precursor proliferation in the cerebellum by Sonic Hedgehog. Neuron 22:103-114.

Xu Q, Wonders CP, Anderson SA (2005) Sonic hedgehog maintains the identity of cortical interneuron progenitors in the ventral telencephalon. Development 132:4987-4998.

Xu Q, Guo L, Moore H, Waclaw RR, Campbell K, Anderson SA (2010) Sonic hedgehog signaling confers ventral telencephalic progenitors with distinct cortical interneuron fates. Neuron 65:328-340. 